\title{
Mechanical seed processing improves the seed quality and reduces Karnal Bunt in seed lots of wheat cultivars
}

\author{
Guru Dayal ${ }^{1 *}$, Amit Kumar Sharma ${ }^{1 *}$, Chandra Nath Mishra ${ }^{1}$, Umesh Ravindra Kamble ${ }^{1}$, Ravindra \\ Kumar $^{1}$ and Shailendra Singh Gaurav
}

Department of Seed Science and Technology, CCS University (Campus) Meerut

${ }^{1}$ ICAR-Indian Institute of Wheat and Barley Research, Karnal 132001 (Haryana), India

\section{Article history:}

Received: 30 July, 2021

Revised: 22 Aug., 2021

Accepted: 01 Sept., 2021

\section{Citation:}

Dayal G, AK Sharma, CN Mishra, UR Kamble, R Kumar and SS Gaurav. 2021. Mechanical seed processing improves the seed quality and reduces Karnal Bunt incidence in seed lots of varied wheat cultivars. Regime for up-scaling global seed trade. Journal of Cereal Research 13 (Spl-1): 51-56. http://doi.org/10.25174/25822675/2021/115260

*Corresponding author: E-mail: gurudayalkumar8175@gmail.com umeshiari@gmail.com

\begin{abstract}
Quality seed production differs from commercial or grain crop production in several aspects. Special methods, precautions and operations are needed to deploy to produce seed of optimum quality. Seed processing influences the quality as well as marketability of seed and could be effectively deployed for elimination of diseased and damaged seeds from healthy seeds. Karnal Bunt (KB) of wheat is an internationally regulated disease and adversely affects the yield, seed appearance and trade. Therefore, effective seed testing and processing is vital to check the spread of disease through the seed. In the present study, efficacy of mechanical seed processing with recommended screen sizes were tested in six different wheat varieties and found that DBW-222 and DBW-187 shown highest recovery percentage of 90 and 89\%, respectively. HD-2967 and HD3086 recorded seed recovery of 87 and $86 \%$, respectively. Lowest recovery was observed in case of durum wheat variety i.e. DDW-47 (85\%). Further, eleven seed lots were tested for eight seed quality parameters and it was found that all carry over and fresh seed lot maintained germination above Indian Minimum Seed Certification Standards i.e. 85\%. Further, processed seed lot showed lower KB infection as compared to un-processed seed lots, being minimum in processed seed lot of DBW-187 (0.15\%) produced at Meerut. However, seed lot of DBW-187 and DBW-222 produced at Karnal recorded $0.17 \% \mathrm{~KB}$ incidence, followed by HD-3086 and HD-2967 $(0.18 \%)$ both produced at Meerut. Further, DDW-47 recorded $0.23 \%$ of KB incidence which was higher among all the varieties after processing. Among two methods adopted for $\mathrm{KB}$ detection, $\mathrm{NaOH}$ method was found to be more sensitive (processed as well as un-processed seed lots) as compared to dry inspection method.
\end{abstract}

Key words:Karnal bunt, $\mathrm{NaOH}$ method, seed lot and seed processing

\section{Introduction}

Wheat is a major cereal crop in several parts of the world. It belongs to the Poaceae family, of which there are many thousands of species, with bread wheat $(T$. aestivum) and durum wheat ( $T$. durum) being the most important commercially (McKevith, 2004). Wheat plays an important role in food supply to the growing world population, and contributes towards $20 \%$ of total protein and calories requirement (Shewry and Hey, 2015). Approximately one-sixth of the total arable land in the world is cultivated with wheat covering all the continents of the world. According to FAOSTAT (2019), China is the highest wheat producer, followed by India, Russia 
and the United States. In India, all the three species of wheat (T. aestivum, T. durum and T. diccocum) are cultivated. It has been under cultivation in the Indian subcontinent from pre-historic times and is an integral part of the food security (Sendhil et al., 2012). Uttar Pradesh, Punjab, Haryana and Madhya Pradesh are the top four wheat producing states constituting about $60 \%$ of the total wheat cultivation in India. As per $4^{\text {th }}$ advance estimate of 202021 given by DAC\&FW, total wheat production in India is 109.52 million tonnes (Anonymous, 2021).

Seed is considered as a key input, having a crucial role in assuring food security. Seed decides fate of all other agricultural inputs viz., irrigation, fertilizer, labour etc. and efficacy of all these inputs revolves around viability and vigour of seed. Quality seed is an important factor for realizing potential productivity by ensuring good germination, rapid emergence and vigorous growth thereby good crop stand and quality seed alone contributes about $15-20 \%$ to the crop productivity (Chauhan et al., 2016). Karnal Bunt (KB) is designated seed borne disease of wheat and occurs sporadically leading to substantial qualitative and quantitative loss (Singh et al., 1985, Bedi, 1989). Even one to four percent infection renders grains unfit for human consumption (Mehadi et al., 1973). Considering its importance in quality seed production, Indian Minimum Seed Certification Standards prescribed $0.05 \%$ and $0.25 \%$ as a maximum permissible limit of $\mathrm{KB}$ incidence in foundation and certified seed respectively. Karnal Bunt infection is effectively reduced during seed processing and more than $93 \%$ of bunted seeds is reported to be separated using gravity separator (Kumar et al., 2015). Seed processing is effective in upgrading the wheat seed lot irrespective of production year and variety (Sinha et al., 2001). Therefore, in the present study, efficacy of mechanical seed processing in reducing Karnal Bunt incidence and efficient detection method of Karnal Bunt in seed lots of different wheat varieties is reported.

\section{Material and Methods}

The seed samples of 8 wheat varieties viz., DBW-187, DBW-222, DBW-173, DBW-252, HD-2967, HD3086, DDW-47(durum) and PBW-723 were collected from the ICAR-IIWBR Karnal \& CPRI- RS Meerut. Further, two stage (seed grader and gravity separator) seed processing of six unprocessed seed lots of $20.0 \mathrm{q}$ of five wheat varieties viz., DBW-222, DBW-187, HD2967, HD-3086 and DDW-47 (durum) was carried out with the small mobile seed processing unit (Agrosaw Model) having a capacity of 0.5 tonnes per hour (TPH). Different seed quality parameters viz, physical purity $(\%)$, germination $(\%)$, seedling length $(\mathrm{mm})$, seedling dry weight $(\mathrm{mg})$, vigour index- I and II, seed protein $(\%)$ and moisture content were determined in 11 seed lots of eight varieties. Wherein, seed processing and seed recovery (\%) was determined in 06 seed lots of five different varieties viz., DBW222, DBW187, HD2967, HD3086 and DDW47 (durum). Further, unprocessed and processed seed lots (06) from five wheat varieties viz., DBW222, DBW187, HD2967, HD3086 and DDW47 (d) were screened for KB infection using dry method and $\mathrm{NaOH}$ method.

Seed quality parameters viz., physical purity (\%) and germination $(\%)$ were calculated as specified in ISTA Rules (2015). Purity analysis was done on working sample of $120 \mathrm{~g}$ and reported as percentage on weight basis of pure seed component. Four replicates of 100 seeds i.e. 400 seeds were kept in between paper (BP) under seed germinator and number of normal seedlings were calculated and reported as germination (\%) as per ISTA Rules, 2015. Moisture and protein content in seed was estimated using Near Infra-Red System (NIR) at Grain Quality Laboratory, ICAR-IIWBR Karnal. $100.0 \mathrm{~g}$ sample was used for estimation of moisture and protein content using NIR method. Shoot and root length was recorded in 10 normal seedlings and mean length per seedling was determined. Seedling vigour index was calculated by using seedling growth parameters and expressed as a whole number as reported by Abdul-Baki and Aderson (1973). Karnal Bunt Testing was done using Dry inspection and $\mathrm{NaOH}$ Method by soaking $100 \mathrm{~g}$ seeds in $0.2 \% \mathrm{NaOH}$ for $24 \mathrm{~h}$ at $20^{\circ} \mathrm{C}$ (Mathur and Cunfer, 1993). KB infection in seed was measured using naked eye method. Eleven processed seed lots of eight wheat varieties produced at Karnal and Meerut including five seed lots of carry over seed of HD 2967, DBW 222, DBW 252, DBW 173 and PBW 723 were analyzed for 8 seed quality parameter and data were subjected to the statistical analysis (Gomez and Gomez, 1984). 


\section{Results and Discussion}

\subsection{Seed quality parameters in eight wheat varieties}

Analysis of variance presented in table 1 revealed that significant differences were found among different seed lots for different seed quality parameters except for moisture content $(\%)$ and physical purity (\%). Highest germination (\%) was recorded in fresh seed lot of DBW187 produced at Karnal and HD3086 produced at Meerut. Whereas, lowest germination was recorded in carry over seed lot of HD 2967. However, all the seed lots recorded germination above IMSCS i.e. 85.0\%. Further, highest seed vigour index-I was recorded in DBW173 (25587.6) followed by DBW222 (25237.6) whereas lowest in carry over seeds of HD2967 (17840.70). Similarly, highest vigour index II was recorded in carry over seeds of DBW222 (1726.6) and lowest in carry over seeds of HD2967 (1433.1). Highest real planting value is observed in case of fresh seed lot of HD3086 (97.9) produced at Meerut whereas lowest real planting value was observed in carryover seed lot of HD2967 (90.2). Highest protein content was observed in DBW187 (15.7\%) followed by DDW47 (15.1\%) and HD3086 (15.0\%).

Table 1. Different seed quality parameters of eleven seed lots in wheat

\begin{tabular}{|c|c|c|c|c|c|c|c|c|c|c|c|}
\hline $\begin{array}{l}\dot{0} \\
\dot{z}\end{array}$ & 窇 & 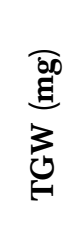 & 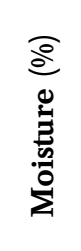 & $\begin{array}{l}\bar{a} \\
\stackrel{\Xi}{0} \\
\frac{\pi}{0} \\
0 \\
0\end{array}$ & 总 & 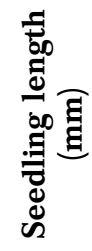 & 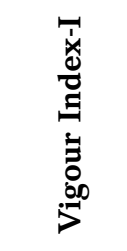 & 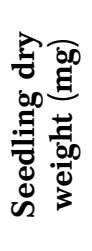 & 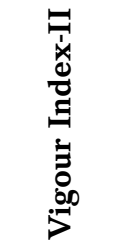 & 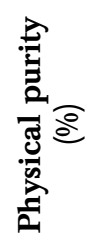 & 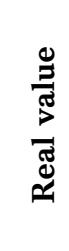 \\
\hline 1 & DBW-173 (CO) & 43 & 11.3 & 12.5 & 97.7 & 261.9 & 25587.6 & 16.9 & 1651.1 & 99.4 & 97.0 \\
\hline 2 & DBW-187 (K) & 46 & 11.4 & 12.9 & 98.3 & 205.8 & 20230.1 & 16.9 & 1661.3 & 99.2 & 97.5 \\
\hline 3 & DBW-187 (M) & 46 & 11.4 & 15.7 & 96.7 & 220.5 & 21322.4 & 16.7 & 1614.9 & 99.6 & 96.3 \\
\hline 4 & DBW-222 (CO) & 42 & 11.2 & 12.0 & 97.0 & 216.1 & 20961.7 & 17.8 & 1726.6 & 99.3 & 96.4 \\
\hline 5 & DBW-222 (K) & 45 & 11.7 & 11.9 & 98.7 & 255.7 & 25237.6 & 16.9 & 1668.0 & 99.1 & 97.8 \\
\hline 6 & DBW-252 (CO) & 45 & 11.2 & 12.3 & 95.7 & 254.7 & 24374.8 & 14.7 & 1406.8 & 99.5 & 95.1 \\
\hline 7 & PBW-723 (CO) & 47 & 11.2 & 12.1 & 97.3 & 216.1 & 21026.5 & 16.8 & 1634.6 & 99.4 & 96.8 \\
\hline 8 & DDW-47 (K) & 51 & 11.4 & 15.1 & 96.0 & 244.0 & 23424.0 & 16.1 & 1545.6 & 99.6 & 95.6 \\
\hline 9 & HD 2967 (M) & 38 & 11.6 & 13.7 & 97.3 & 256.0 & 24908.8 & 16.1 & 1566.5 & 99.2 & 96.6 \\
\hline 10 & HD-2967 (CO) & 44 & 11.2 & 11.7 & 90.7 & 196.7 & 17840.7 & 15.8 & 1433.1 & 99.5 & 90.2 \\
\hline \multirow[t]{7}{*}{11} & HD-3086 (M) & 36 & 11.5 & 15.0 & 98.3 & 215.0 & 21134.5 & 16.2 & 1592.5 & 99.6 & 97.9 \\
\hline & Range: & 36 & 11.2 & 11.7 & 90.7 & 196.7 & 17840.7 & 14.7 & 1433.1 & 99.1 & 95.1 \\
\hline & Max & 51 & 11.7 & 15.7 & 98.7 & 261.9 & 25587.6 & 17.8 & 1726.6 & 99.6 & 97.9 \\
\hline & $\mathrm{CV}$ & 1.20 & 0.98 & 2.67 & 1.42 & 7.50 & 7.50 & 7.07 & 7.80 & 0.25 & 1.17 \\
\hline & $\mathrm{SE}(\mathrm{d})$ & 0.43 & 0.09 & 0.29 & 1.12 & 13.98 & 1348.29 & 0.97 & 103.23 & 0.20 & 0.80 \\
\hline & LSD 5\% & 0.74 & $\mathrm{NS}$ & 0.50 & 1.94 & 23.91 & 2325.43 & 1.66 & 178.04 & NS & 1.37 \\
\hline & LSD $1 \%$ & 1.09 & $\mathrm{NS}$ & 0.73 & 2.84 & 34.83 & 3408.46 & 2.41 & 260.96 & NS & 2.01 \\
\hline
\end{tabular}

\#CO- carry over seed; $\boldsymbol{K}$ - Seed produced at Karnal; $\boldsymbol{M}$ - Seed Produced at Meerut, $\mathbf{T}$ GW- Test Grain Weight

\subsection{Seed processing of five wheat varieties}

Seed processing of five wheat varieties revealed that among different types of screens viz, top screen, bottom screen, air lift and gravity separation, the maximum amount of impurity was recorded in bottom screen. The processed seed obtained from bottom screen varied from $92.3 \mathrm{~kg}$ [DBW $222(\mathrm{~K})]$ to $206.0 \mathrm{~kg}$ [DDW 47(K)] (Table 2). The processed seed obtained at bottom screen and gravity separator screen is almost similar in seed lot of DBW $222(\mathrm{~K})(4.6 \%$ and $4.53 \%$, respectively). Whereas, per cent of top screen ranges from $0.064 \%$ [HD2967-(M)] to $0.175 \%$ [DDW47-(K)] and per cent bottom screen ranges from 4.62 [DBW 222(K)] to 10.30 [DDW $47(\mathrm{~K})]$ and lifter screen ranged from 0.84 [DDW222(K)] to $1.79[\mathrm{DBW} 187(\mathrm{~K})]$. Finally, all component of screen very rarely goes beyond $14.7 \%$ as it ranged from 10.1 [DBW222(K)] to $14.7 \%$ [DDW47(K)]. It can be concluded that, on the basis of final processed seed weight, the maximum recovery was recorded in [DBW222-(K)] $(89.9 \%)$ followed by [DBW187-(M)] $(88.8 \%)$ and [DBW187$(\mathrm{K})](88.2 \%)$ wherein minimum seed recovery percentage was recorded in [DDW $47(\mathrm{~K})](85.3 \%)$. 
Table 2. Effect of different screen on recovery percent of different seed lots of wheat varieties

\begin{tabular}{|c|c|c|c|c|c|c|c|c|c|c|c|c|}
\hline \multirow[b]{2}{*}{ Variety } & \multirow{2}{*}{$\begin{array}{c}\text { Weight } \\
\text { seed } \\
(\mathrm{kg}) \\
\end{array}$} & \multicolumn{8}{|c|}{ Quantity $(\mathrm{kg})$ and per cent $(\%)$ of different types of screen } & \multirow{2}{*}{$\begin{array}{c}\text { Final } \\
\text { seed } \\
(\mathbf{k g}) \\
\end{array}$} & \multirow{2}{*}{$\begin{array}{c}\text { Final } \\
\text { Seed } \\
(\%) \\
\end{array}$} & \multirow{2}{*}{$\begin{array}{c}\text { Total } \\
\text { Screen } \\
(\%)\end{array}$} \\
\hline & & $\begin{array}{l}\text { Top } \\
\text { (kg) }\end{array}$ & $\%$ & $\begin{array}{c}\text { Bottom } \\
(\mathrm{kg})\end{array}$ & $\%$ & $\begin{array}{c}\text { Lifter } \\
\text { (kg) }\end{array}$ & $\%$ & $\begin{array}{c}\text { GS } \\
(\mathrm{kg})\end{array}$ & $\%$ & & & \\
\hline DBW-222 K & 2000 & 1.5 & 0.075 & 92.3 & 4.62 & 16.75 & 0.84 & 90.5 & 4.53 & 1798.9 & 89.9 & 10.1 \\
\hline DBW-187M & 2000 & 1.6 & 0.080 & 171.8 & 8.59 & 35.78 & 1.79 & 14.8 & 0.74 & 1776.0 & 88.8 & 10.2 \\
\hline DBW-187 K & 2000 & 2.5 & 0.125 & 190.5 & 9.23 & 23.50 & 1.18 & 18.6 & 0.93 & 1764.9 & 88.2 & 10.8 \\
\hline HD-2967M & 2000 & 1.3 & 0.064 & 195.4 & 9.77 & 21.20 & 1.06 & 40.1 & 2.01 & 1742.0 & 87.1 & 12.9 \\
\hline HD-3086M & 2000 & 2.7 & 0.135 & 200.0 & 10.00 & 30.50 & 1.53 & 50.6 & 2.53 & 1716.2 & 85.8 & 14.2 \\
\hline DDW-47 K & 2000 & 3.5 & 0.175 & 206.0 & 10.30 & 35.00 & 1.75 & 50.0 & 2.50 & 1705.5 & 85.3 & 14.7 \\
\hline \multirow{2}{*}{ Range } & Min. & 1.3 & 0.064 & 92.3 & 4.62 & 16.75 & 0.84 & 14.8 & 0.74 & 1705.5 & 85.3 & 10.1 \\
\hline & Max. & 3.5 & 0.175 & 206.0 & 10.30 & 35.78 & 1.79 & 90.5 & 4.53 & 1798.9 & 89.9 & 14.7 \\
\hline Mean & & 2.18 & 0.11 & 176.00 & 8.75 & 27.12 & 1.36 & 42.92 & 2.21 & 1750.6 & 87.52 & 12.15 \\
\hline $\mathrm{CV}$ & & 39.34 & 39.59 & 24.22 & 24.14 & 28.76 & 28.68 & 70.99 & 62.16 & 2.06 & 2.03 & 16.91 \\
\hline
\end{tabular}

GS- Gravity Separator; \#CO- carry over seed; K- Seed produced at Karnal; M- Seed Produced at Meerut

\subsection{Karnal Bunt incidence in un-processed and processed seed lot of five wheat varieties}

Karnal Bunt is a major and objectionable seed born disease in wheat which needs to be in the within permissible limit as prescribed by IMSCS. It is always desired that seed produced should be free from seed borne disease to check its spread in subsequent generations. KB disease is known to adversely affect the size and density of seed. Intensity of disease in the seed is variable and highly dependent on environmental factors at flowering. The portion of wheat grain affected with $T$. indica is transformed into fungal teliospores and appears black powdery (Kumar $e t$ al., 2015). The analysis of different grades of infection of $\mathrm{KB}$ on wheat seeds showed that higher disease intensity on the seed leads to lower 1000 seed weight, seedling length, germination and vigour. Singh (1980) confirmed that with increased disease intensity of there was gradual decrease in seed weight, seedling length and germination. Differences in size and aerodynamic behavior could be effectively utilized for separation of seeds infected with KB (Kumar et al., 2015).
Unprocessed and processed seed samples of 6 lots from five wheat varieties viz, DBW222, DBW187, HD2967, HD3086 and DDW47 (durum) have been analyzed and presented in the table 3 which indicated that, $\mathrm{KB}$ infection ranged from $0.15-0.57$ in unprocessed seed as detected using dry method whereas the infection of $\mathrm{KB}$ increased when detected by $\mathrm{NaOH}$ method $[0.17 \%$ (DBW $222 \mathrm{~K})-0.67 \%$ (DBW 187K)]. Processed seed lots showed reduced $\mathrm{KB}$ infection as compared to un-processed seed lots which is in conformity with previous study conducted by Kumar et al., (2015), being minimum in processed seed lot of DBW-187 (0.15\%) produced at Meerut. However, seed lot produced at Karnal of DBW-187 and DBW-222 variety recorded $0.17 \%$ incidence, followed by HD-3086 and HD-2967 (0.18\%) both produced at Meerut. Further, DDW-47 recorded $0.23 \%$ of KB incidence which was higher among all the varieties after processing. Among two methods adopted for $\mathrm{KB}$ detection, $\mathrm{NaOH}$ method was found to be more sensitive as compared to dry inspection method. This clearly indicated that, $\mathrm{NaOH}$ method is more useful and sensitive in detection of $\mathrm{KB}$ in processed as well as un-processed seed.

Table 3. Karnal bunt infection in u nprocessed and processed seed lots

\begin{tabular}{ccccc}
\hline \multirow{2}{*}{ Variety } & \multicolumn{2}{c}{ Dry Method } & \multicolumn{2}{c}{ NaOH Method } \\
\cline { 2 - 5 } & Unprocessed & Processed & Unprocessed & Processed \\
\hline HD-3086 (M) & 0.16 & 0.15 & 0.28 & 0.18 \\
HD-2967 (M) & 0.15 & 0.11 & 0.22 & 0.18 \\
DBW-187 (M) & 0.22 & 0.02 & 0.67 & 0.15 \\
DBW-187(K) & 0.18 & 0.15 & 0.27 & 0.17 \\
DBW-222 (K) & 0.44 & 0.15 & 0.17 & 0.17 \\
DDW-47 (K) & 0.57 & 0.20 & 0.33 & 0.23 \\
\hline
\end{tabular}


Mechanical seed processing improves seed quality in wheat

\begin{tabular}{ccccc}
\hline Range & $0.15-0.57$ & $0.02-0.20$ & $0.17-0.67$ & $0.15-0.23$ \\
CV & 28.67 & 23.91 & 29.65 & 16.77 \\
S.E (d) & 0.07 & 0.03 & 0.08 & 0.02 \\
LSD (5\%) & 0.12 & 0.05 & 0.14 & 0.04 \\
LSD (1\%) & 0.18 & 0.07 & 0.22 & 0.07 \\
\hline
\end{tabular}

( $\mathrm{M}$ and $\mathrm{K}$ in table 3 symbolizes seeds produced at Meerut and Karnal, respectively).

\section{Conclusion}

Although KB infection is largely managed at the time of production by pro-phyletic spraying/measures, it can be effectively removed by the mechanical seed processing as the infected seeds appears light as compared to healthy seed due to transformation of seed into black powdery spores. Considering differences in seed density of infected seeds, gravity separator can be effectively utilized for separation of infected seeds from healthy seeds. Among two methods, adopted for $\mathrm{KB}$ detection, $\mathrm{NaOH}$ method was found to be more effective as compared to dry inspection method.

\section{Acknowledgements}

Author acknowledges Director, ICAR- Indian Institute of Wheat and Barley Research for support and making available resources for successful conductance of referred experiment.

\section{Conflict of Interest}

Authors declare that they have no conflict of interest.

\section{Ethical Compliance Statement}

NA

\section{Author's Contribution}

Conceptualization (AKS \& SSG); Designing of experiment (AKS and CNM), Execution of field/lab experiments and data collection (GD\& RK), Analysis of data and interpretation (GD, AKS, URK); Preparation of the manuscript (GD, URK, CNM and AKS).

\section{References}

1. Abbul-Baki AA and JD Anderson. 1973. Vigour determination in soybean seed by multiple criteria. Crop Science 13: 630-633 https://doi.org/10.2135/cr opsci1973.0011183X001300060013x

2. Anonymous. 2021. $4^{\text {th }}$ Advance Estimates of production of Food grains, Oilseeds and Other Commercial Crops for the year 2020-21 published by Department of Agriculture and Cooperation and
Farmers' Welfare, GOI. (https://eands.dacnet.nic. in/Advance_Estimate/ Time $\% 20$ Series $\% 203 \% 20$ AE. $\% 202020-21 \% 20$ English.pdf)

3. Bedi PS. 1989. Impact of new Agricultural Technology on Karnal Bunt of wheat in Punjab. Plant Disease Research 4:1-8

4. Beniwal MS, P Chawla, S Madan and R Singh. 2000. Effect of Karnal Bunt on grain weight and quality of wheat. Annals of Biology 16: 101-104

5. Chauhan JS, PS Rajendra, S Pal, PR Choudhury and K. Udaya Bhaskar. 2016. Seed production of field crops in India: Quality assurance, status, impact and way forward. Indian Journal of Agricultural Sciences, 86 (5): 563-579

6. Food and Agriculture Organization. 2019. FAOSTAT Statistical Database of the United Nation Food and Agriculture Organization (FAO) Statistical Division. Rome.

7. Gill KS, I Sharma and SS Aujla. 1993. Karnal Bunt and wheat production. Published by Punjab Agricultural University, Ludhiana, India, 1-153.

8. Gomez, KA and AA Gomez. 1984. Statistical procedures for agricultural research ( $2^{\text {nd }}$ ed.). John wiley and sons, NewYork, 680p.

9. International Rules of Seed Testing. 2015. (Published by ISTA, Zurich, Switzerland)

10. Kumar A, A Gupta, SS Atwal, VK Maheshwari and CB Singh. 2015. Post-harvest management of Karnal Bunt, a quarantine disease in India. Plant Pathology Journal 14 (1):23-30

11. Kumar R and B Koli. 2015. Effectiveness of Seed Processing Machinery on Seed Quality Improvement in Wheat (Triticum aestivum L.) Journal of Agrisearch 2(4): 300-303

12. Mathur SB and BM Cunfer. 1993. Seed Borne Diseases and Seed Health Testing of Wheat. Danish 
Govt. Institute of Seed Pathology for Developing Countries, Copenhagen, 168

13. McKevith B. 2004. Nutritional aspects of cereals. British Nutrition Foundation Nutrition Bulletin 29: 111-142

14. Mehadi V, LM Worhi and YP Abrol. 1973. Studies on chapati making quality. VI. Effect of wheat grains with Bunts on the qualities of chapatti. Bulletin Grain Technology. 11: 195-197

15. Sendhil R, R Singh and I Sharma. 2012. Exploring the performance of wheat production in India. Journal of Wheat Research 4(2): 37-44.

16. Shewry PR and SJ Hey. 2015. The contribution of wheat to human diet and health. Food and Energy Security 4(3): 178-202
17. Singh DV, KD Srivastava and LM Joshi.1985. Present status of Karnal Bunt of wheat in relation to its distribution and varietal susceptibility. Indian Phytopathology, 507-515.

18. Singh D. 1980. Note on the effect of Karnal bunt infection on vigour of wheat seed. Seed Research 8: 81-82.

19. Sinha JP, BS Modi, RP Nagar, SN Sinha and M Vishwakarma. 2001. Wheat seed processing and quality improvement. Seed Research 29: 171-178.

20. Trivedi RK and M Gunasekaran. 2013. Indian minimum seed certification standards. Published by Central Seed Certification Board, Department of Agriculture and Co-operation, Ministry of Agriculture, Government of India, 1-569. 